\title{
Acute Aortic Dissection in Third Trimester Pregnancy with Well Controlled Hypertension
}

\author{
Dongping Xie, Guixian Chen*, Xudong Dong \\ Department of Obstetrics and Gynecology, The First People's Hospital of Yunnan Province, The Affiliated Hospital of Kunming \\ University of Science and Technology, Kunming, China \\ Email: ${ }^{\star}$ gx.chenkm@outlook.com
}

How to cite this paper: Xie, D.P., Chen, G.X. and Dong, X.D. (2021) Acute Aortic Dissection in Third Trimester Pregnancy with Well Controlled Hypertension. Case Reports in Clinical Medicine, 10, 330-337. https://doi.org/10.4236/crcm.2021.1010042

Received: September 8, 2021

Accepted: October 26, 2021

Published: October 29, 2021

Copyright $\odot 2021$ by author(s) and Scientific Research Publishing Inc. This work is licensed under the Creative Commons Attribution International License (CC BY 4.0).

http://creativecommons.org/licenses/by/4.0/

\begin{abstract}
We describe a 32-year-old pregnant woman at $31+6$ weeks of gestation who presented to a tertiary-care hospital with headache and back pain. She was found to have a sign of tear about $1.3 \mathrm{~cm}$ away from the aortic valve, and the torn intima extended upward to the ascending aorta and the descending part of the aortic arch. She delivered a live male neonate via cesarean delivery. She had a history of hypertension with oral Labetalol $50 \mathrm{mg}$ twice times daily. At the very beginning of the onset, physicians in the emergency room wouldn't be aware of the symptoms of aortic dissections, as well as atypical presentations which include anterior chest pain or chest pain radiating to the back. She was only received anti-hypertension management, until her symptoms of back pain aggravated, and an aortic dissection was confirmed by ultrasound and CT angiography. Then she received a mechanical aortic valve replacement. After 51 days of treatment, she was discharged and recovered without any complications. Aortic dissection in pregnancy is a rare disease. We recommend transthoracic echocardiography every 1 to 2 months to monitor the diameter of the ascending aorta during pregnancy in which patients with hypertension problems or other risk factors of aneurysm and perform the CT angiography scan to confirm aortic dissection in a pregnant or postpartum woman with suspicious pain symptoms. It is essential that multidisciplinary approach in which teams must urgently collaborate to ensure the protection life of both mother and baby.
\end{abstract}

\section{Keywords}

Acute Aortic Dissection, Pregnancy, Hypertension

\section{Introduction}

Aortic dissection (AD) in pregnancy is a rare disease, usually occurring in the ${ }^{*}$ Corresponding author. 
third trimester and early postpartum period, with an incidence rate of $14.5 /$ million [1]. It is a life-threatening condition for both mother and fetus, and its mortality rates of $30 \%$ and $50 \%$ respectively [2]. It also ranks the third most frequent cause of maternal death due to cardiovascular disease [3]. As we know that the normal human arterial vessels are composed of three layers, intima, media and adventitia, which are closely fitted together to carry blood flow through. AD refers to the gradual dissection and expansion of the intima due to the local tear of the intima and the strong blood impact, forming the true and false cavities in the artery [4]. The most common causes for $\mathrm{AD}$ are venous thromboembolism and cardiac arrhythmias, pre-eclampsia/eclampsia, severe sepsis, amniotic fluid embolism, hemorrhage, trauma, and pre-existing heart disease [3] [4]. Hypertension and Marfan syndrome are the main causes of pregnancy complications with $\mathrm{AD}$ [5]. However, even in the well-controlled hypertension, $\mathrm{AD}$ needs to be considered when evaluating sudden severe head and back pain in the pregnant patient. We present a case of acute Stanford A aortic dissection (type A aortic dissection, TAD) in a previously well controlled hypertension pregnant patient.

\section{Case Presentation}

A 32-year-old woman, G4P2A1, presented at $31+6$ weeks gestation to the emergency department after sudden onset of head and back pain, dizziness for 29 hours and the back pain progressive aggravation for 5 hours with nausea. Her pregnancy had been complicated by pregnancy-induced hypertension treated with Labetalol $50 \mathrm{mg}$ twice times daily. She had no appearance of Marfan syndrome, no other medical, or drug-use history, and she delivered a term health baby via cesarean section at four years ago. Her heart rate was 80 beats per minute, blood pressure $190 / 110 \mathrm{mmHg}$, respiratory rate 22 breaths per minute, with $\mathrm{SpO}_{2} 91 \%$. Her height was $150 \mathrm{~cm}$ and weight $56 \mathrm{~kg}$. On physical exam, the patient had gravid abdomen. The uterine height was $25 \mathrm{~cm}$ and the abdominal circumference was $90 \mathrm{~cm}$. The fetal heart was 140 beat $/ \mathrm{min}$, irregular contractions, on vaginal examination, the cervix was $2 \mathrm{~cm}$ and the uterine orifice was not opened, as well as the fetal membrane was not broken, and both lower limbs were not edema.

The patient immediately received antihypertension treatment which were including urapidil $50 \mathrm{mg}$ mixed with $50 \mathrm{ml}$ solution, intravenously pumped 5 $\mathrm{ml} / \mathrm{h}$, Labellol $150 \mathrm{mg}$, nifedipine controlled-release tablets $30 \mathrm{mg}$ orally and Magnesium sulfate $20 \mathrm{~g}$ to relieve spasmolysis. Then, her blood pressure reached to $156 / 96 \mathrm{mmHg}$ after treated $30 \mathrm{~min}$. After initial management, the patient's headache released, but the neck and back pain did not relieve. Her initial total white blood cell account was $12.44 \times 10^{9} / \mathrm{L}$ and hemoglobin was $93 \mathrm{~g} / \mathrm{L}$. Her activeated partial thromboplasting time was $37.3 \mathrm{~s}$. On liver function, Lactate dehydrogenase was $254 \mathrm{U} / \mathrm{L}$. On renal function, Uric acid was $527 \mathrm{umol} / \mathrm{L}$, no proteinuria. On Myocardial enzyme spectrum test, Troponin I was $0.022 \mathrm{ng} / \mathrm{mL}$, Myog- 
lobin $121.0 \mathrm{ng} / \mathrm{mL}$ and B-type natriuretic peptide was $569 \mathrm{pg} / \mathrm{mL}$. A bedside echocardiography showed that the aortic sinus was significantly widened with $42.4 \mathrm{~mm}$, and the ascending aorta was widened with $19.3 \mathrm{~mm}$. Moderate aortic regurgitation sign and pericardial fluid. There were signs of intimal tear about $1.3 \mathrm{~cm}$ away from the aortic valve, and the torn intima extended upward to the ascending aorta and the descending part of the aortic arch. Computerized tomography angiography of the aorta showed that the Double lumen shadow was seen from the ascending aortic root to the left common iliac artery, which involved the brachiocephalic trunk, bilateral common carotid artery, proximal right external and internal carotid artery, and proximal left subclavian artery. There was found the clot inside the common hepatic artery with blood perfusion to hepatic was blocked. As this result, Acute Aortic Dissection (Stanford type A) was considered (Figure 1 and Figure 2).

This complex clinical scenario was immediately handled by a multidisciplinary team consisting of obstetricians, cardiovascular surgeons, anesthesiologists, neonatologists, patient and her family members. After this Emergency Department multidisciplinary team consultations, make a clinical decision making as follows to save both life of mother and fetus: the obstetrical team performed an emergent cesarean delivery, then, the cardiothoracic surgical team concurrently performed David procedure with Sun's procedure (a total arch replacement using a tetrafurcated graft with implantation of a special stented elephant trunk implantation in the descending aorta). During the whole surgical process, general anesthesia was induced with the patient in the supine position and blood

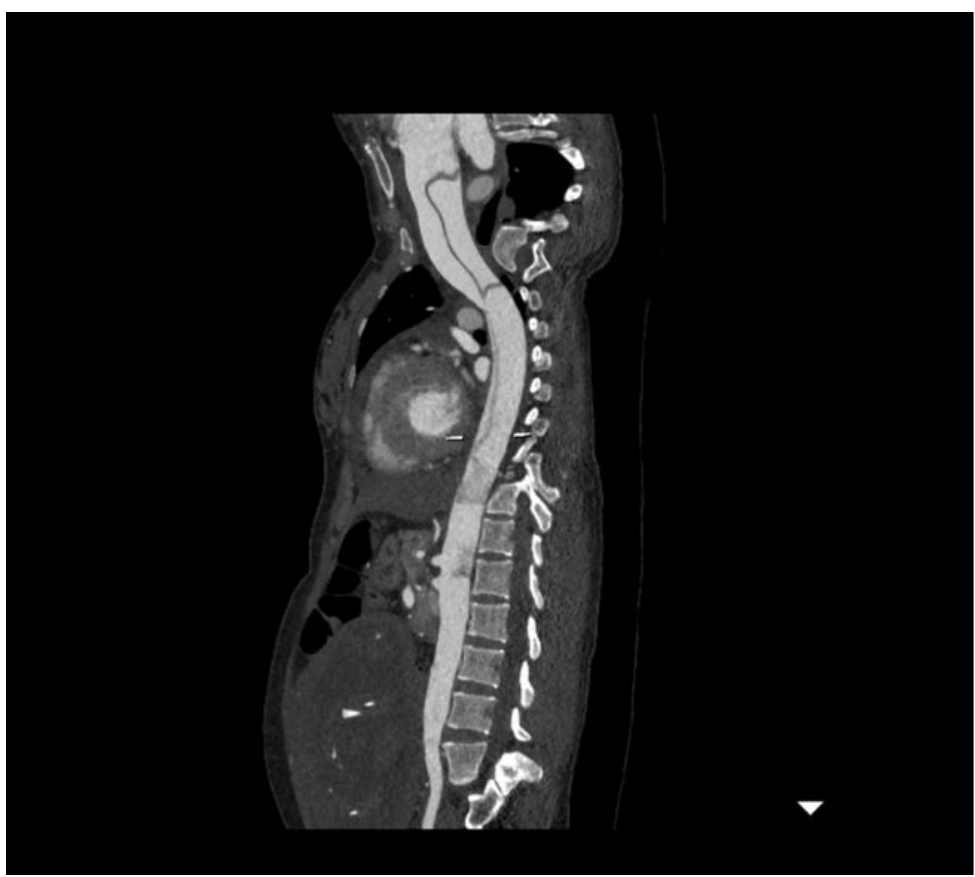

Figure 1. CT Multiplane reconstruction (MPR) demonstrates low-density shadows caused by endointimal displacement in the active vessels of the chest and abdomen. 


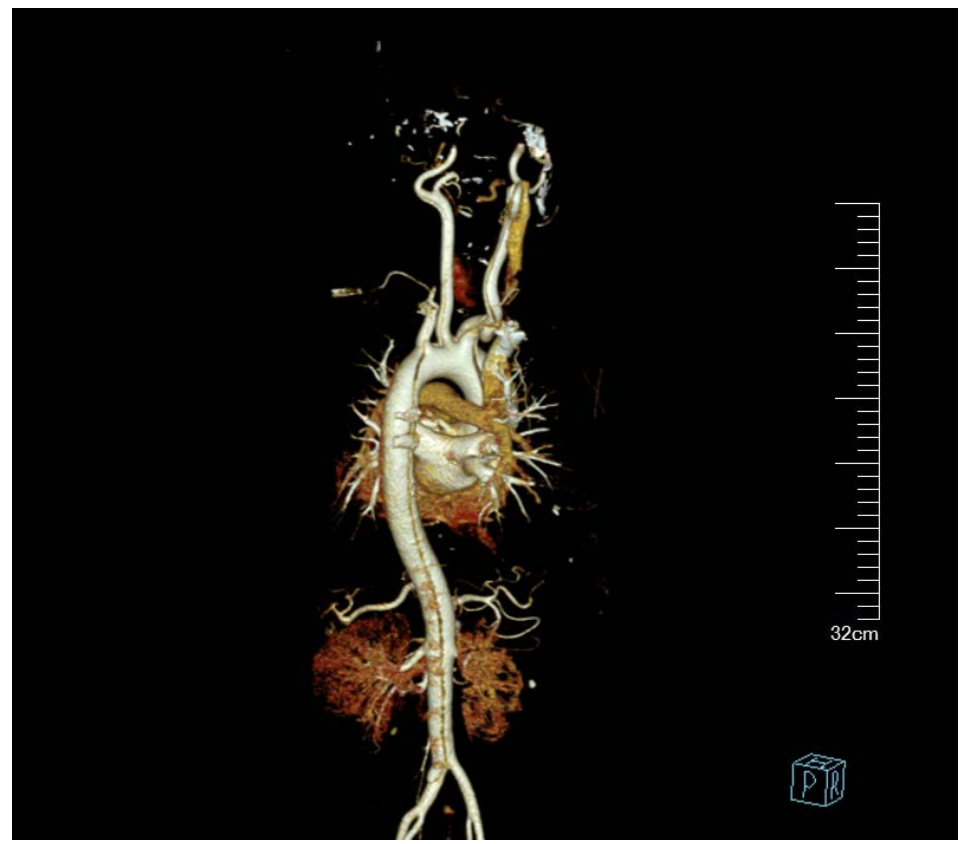

Figure 2. 3D reconstruction: dissection of thoracic and abdominal aorta was observed, and bilateral common carotid arteries and left subclavian artery were also involved.

pressure in the left radial artery and left femoral artery was monitored. The delivered preterm neonate was sent to Neonatal Intensive Care Unit. This treatment plan obtained the total consent from patient and her family members.

During cesarean surgery, the cardiothoracic surgeon got ready to initiate extracorporeal circulation with axillary/femoral artery and femoral vein intubation in the event of hemodynamic instability. After the cesarean section, the obstetrical team performed the uterine artery ligation, uterine gauze tamponade and uterine ring binding to prevent uterine bleeding after cesarean section. The gauze was removed 36 hours after operation. In the process of cardiothoracic process, extracorporeal circulation time was 207 minutes, aortic cross-clamp was 106 minutes, antegrade selective cerebral perfusion was 20 minutes with lowest nasal temperature was $22.4^{\circ} \mathrm{C}$ to $23^{\circ} \mathrm{C}$. Birth weight of survived preterm neonate was $1400 \mathrm{~g}$ and he was transferred to the neonate intensive care unit, after 20 days ventilator assisted breathing, the infant separated from the mechanical ventilation successfully and was discharged home at 37 weeks gestation week. The whole surgery process was successful without any multiple organ dysfunction, serious infections, neurological dysfunctions and other complications. Drainage tubes were indwelled in the mediastinum and pericardium and the ventilator was assisted breathing. Then, the patient was transferred to the Cardiovascular Surgery Intensive Care Unit for further treatment. On the 5th day after surgery, endotracheal intubation was pulled out, and indwelling fluid in mediastinum and pericardium was less than $50 \mathrm{ml}$. The indwelling drainage tube in mediastinum and pericardium was extracted. After 51 days treatment, patient was discharged from hospital with warfarin $10 \mathrm{mg}$ daily. Three months late, the patient returned to 
the hospital for medical examination. CT scan showed that the shape and position of special stented elephant trunk graft is stable without any complications (see Figure 3 and Figure 4).

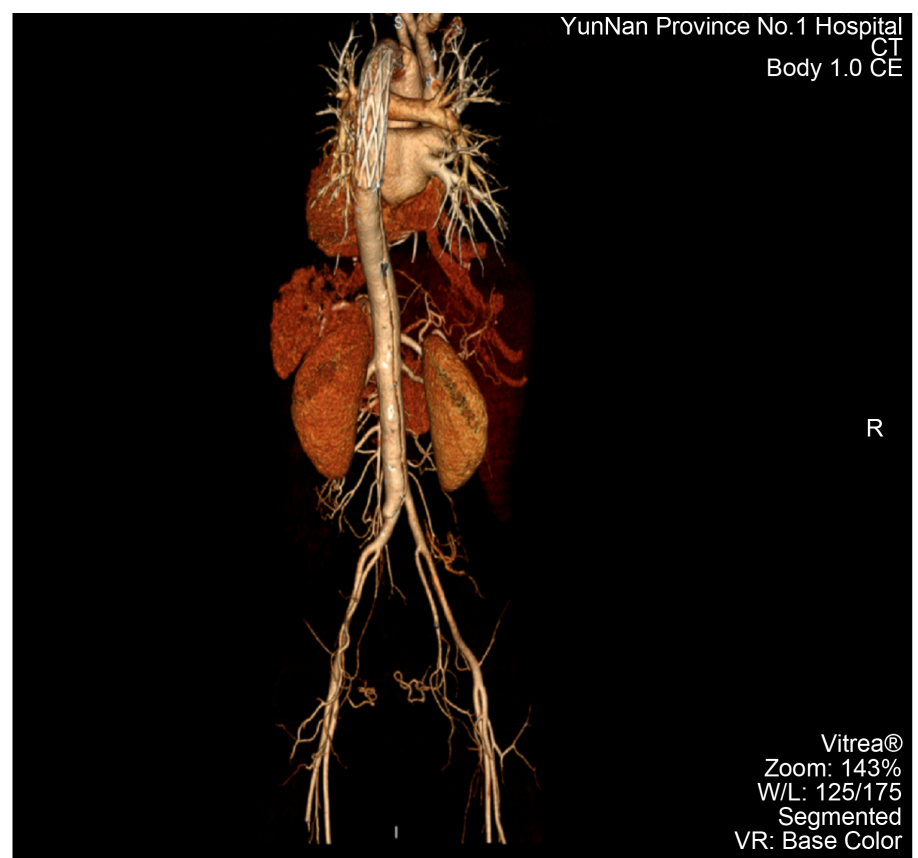

Figure 3. The shape and position of graft is stable by angiography CT scan

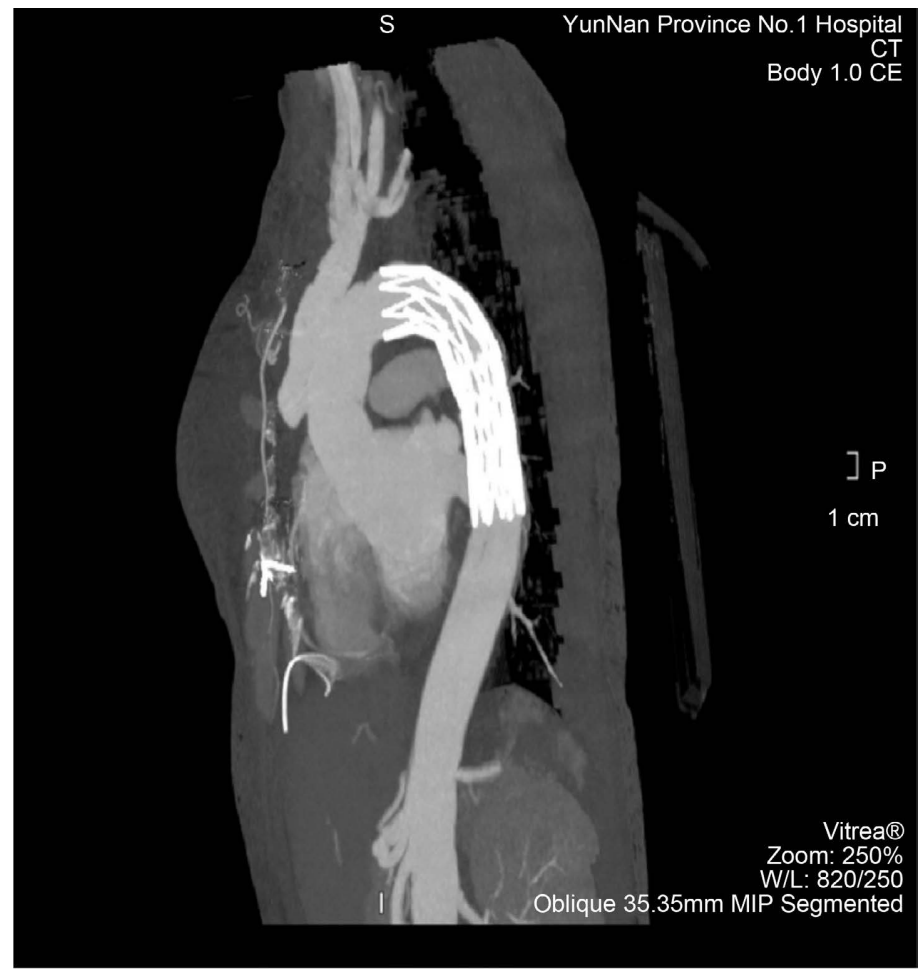

Figure 4. Multiplanar reconstruction demonstrates that the aortic arch and descending vascular lumen are well filled with contrast agents. 


\section{Discussion}

We describe a patient who presented with head and back pain in the third trimester and was diagnosed with preeclampsia and acute Stanford type A aortic dissection. The patient in the present case lacked traditional risk factors for aortic dissection, including Marfan's disease, Ehlers-Danlos syndrome, bicuspid aorta, and Loeys-Dietz syndrome, but she had the history of gestational Hypertension without standard treatments. Because she had delivered a term health baby via cesarean section at four years ago, thus, she didn't pay attention to monitor her blood pressure in this pregnancy period. At the very beginning of the onset, Physicians in the emergency room and patient herself wouldn't be aware of the symptoms of aortic dissections, as well as atypical presentations which include the anterior chest pain or chest pain radiating to the back. In the meantime, the preeclampsia presents with hypertension and headache, potentially masking the presenting features of an acute aortic dissection.

It is well known that the aortic deteriorate widening during pregnancy is a physiological phenomenon that lasts until the early puerperal period. In order to meet the needs of fetal growth and development, the blood volume of pregnant women gradually increases from the 6th week of pregnancy and the blood volume increases by 35 to 45 percent until return to normal after one month postpartum [6]. On the other side, the level of estrogen progesterone increased significantly during pregnancy, resulting in damage to the elastic fibers and collagen in the aortic wall [7]. These factors would lead the vasculature to dissection.

This is a huge challenge to detect and manage of aortic dissection in pregnancy. The outcomes in this case highlight three important points. First, Strict blood pressure control is of paramount importance for all of patient, and we should monitor the aortic root diameter dynamic changes during pregnancy period. According to the ACCF/AHA guidelines for the diagnosis and management of patients with thoracic aortic disease, patients should receive transthoracic echocardiography every 1 to 2 months to monitor the diameter of the ascending aorta during pregnancy and CT angioraphy should be performed at 1, 3, 6, and 12 months postoperatively and every 1 year if pregnancy is terminated [8] [9]. Second, the echocardiogram investigation offers a quick, safe, and accurate means of diagnosis. If patient present abnormal chest pain, headache or back pain, even against a background of preeclampsia, it is essential to immediately investigate such kinds of signs in pregnancy by ultrasound [10] [11] [12]. Finally, although there is the debate on the timing of surgery, but the life of the pregnant woman must be saved as a priority regardless of the situation, and emergency repair surgery must be performed immediately [2] [5] [13] [14]. Therefore, the management of $\mathrm{AD}$ in pregnancy requires a multidisciplinary approach in which teams must urgently collaborate to ensure the protection life of both mother and baby.

\section{Conclusion}

Aortic dissection in pregnancy is a rare disease. We recommend transthoracic 
echocardiography every 1 to 2 months to monitor the diameter of the ascending aorta during pregnancy in which patients with hypertension problems or other risk factors of aneurysm and perform the CT angiography scan to confirm aortic dissection in a pregnant or postpartum woman with suspicious pain symptoms. It is essential that multidisciplinary approach in which teams must urgently collaborate to ensure the protection life of both mother and baby.

\section{Acknowledgements}

We gratefully acknowledge the cardiology, cardiothoracic, and anesthesia teams who assisted in the multidisciplinary care of this patient. We also acknowledge our patient, without whom this case report would not have been possible.

\section{Funding}

The research was supported by the grant from Academician Workstation of Yunnan Province 202005AF150033.

\section{Conflicts of Interest}

The authors have no conflict of interest relevant to this publication.

\section{References}

[1] Prendes, C.F., Christersson, C. and Mani, K. (2020) Pregnancy and Aortic Dissection. European Journal of Vascular and Endovascular Surgery, 60, 309-311. https://doi.org/10.1016/j.ejvs.2020.03.052

[2] Banerjee, A., Begaj, I. and Thorne, S. (2015) Aortic Dissection in Pregnancy in England: An Incidence Study Using Linked National Databases. BMJ Open, 5, e008318. https://doi.org/10.1136/bmjopen-2015-008318

[3] Immer, F.F., Bansi, A.G., Immer-Bansi, A.S., McDougall, J., Zehr, K.J., Schaff, H.V. and Carrel, T.P. (2003) Aortic Dissection in Pregnancy: Analysis of Risk Factors and Outcome. The Annals of Thoracic Surgery, 76, 309-314. https://doi.org/10.1016/S0003-4975(03)00169-3

[4] Thalmann, M., Sodeck, G.H., Domanovits, H., Grassberger, M., Loewe, C., Grimm, M. and Czerny, M. (2011) Acute Type A Aortic Dissection and Pregnancy: A Population-Based Study. European Journal of Cardio-Thoracic Surgery, 39, e159-e163. https://doi.org/10.1016/j.ejcts.2010.12.070

[5] Sterner, D., Probst, C., Mellert, F. and Schiller, W. (2014) Surgical Treatment and Thoracic Endovascular Aortic Repair in Type a Aortic Dissection in a Pregnant Patient with Marfan Syndrome. Annals of Vascular Surgery, 28, P1317.E7-1317.E10. https://doi.org/10.1016/j.avsg.2013.10.011

[6] Yuan, S.M. (2013) Postpartum Aortic Dissection. Taiwanese Journal of Obstetrics and Gynecology, 52, 318-322. https://doi.org/10.1016/j.tjog.2013.06.003

[7] Zhu, J.M., Ma, W.G., Peterss, S., Wang, L.F., Qiao, Z.Y., Ziganshin, B.A., Zheng, J., Liu, Y.M., Elefteriades, J.A. and Sun, L.Z. (2017) Aortic Dissection in Pregnancy: Management Strategy and Outcomes. The Annals of Thoracic Surgery, 103, 1199-1206. https://doi.org/10.1016/j.athoracsur.2016.08.089

[8] Cui, J.-S., Jing, Z.-P., Zhuang, S.-J., Qi, S.-H., Li, L., Zhou, J.-W., Zhang, W., Zhao, Y., Qi, N. and Yin, Y.-J. (2015) D-Dimer as a Biomarker for Acute Aortic Dissec- 
tion: A Systematic Review and Meta-Analysis. Medicine, 94, e471. https://doi.org/10.1097/MD.0000000000000471

[9] Hirata, K., Wake, M., Kyushima, M., Takahashi, T., Nakazato, J., Mototake, H., Tengan, T., Yasumoto, H., Henzan, E. and Maeshiro, M. (2010) Electrocardiographic Changes in Patients with Type A Acute Aortic Dissection: Incidence, Patterns and Underlying Mechanisms in 159 Cases. Journal of Cardiology, 56, 147-153. https://doi.org/10.1016/j.jjcc.2010.03.007

[10] Hiratzka, L., Bakris, G. and Beckman, J. (2013) ACCF/AHA Guideline for the Management of ST-Elevation Myocardial Infarction: Executive Summary: A Report of the American College of Cardiology Foundation/American Heart Association Task Force on Practice Guidelines. Journal of the American College of Cardiology, $61,485-510$

[11] Kosuge, M., Kimura, K., Uchida, K., Masuda, M. and Tamura, K. (2017) Clinical Implications of Electrocardiograms for Patients with Type A Acute Aortic Dissection. Circulation Journal, 81, 1254-1260. https://doi.org/10.1253/circj.CJ-17-0309

[12] Costin, N.I., Korach, A., Loor, G., Peterson, M.D., Desai, N.D., Trimarchi, S., de Vincentiis, C., Ota, T., Reece, T.B. and Sundt, T.M. (2018) Patients with Type A Acute Aortic Dissection Presenting with an Abnormal Electrocardiogram. The Annals of Thoracic Surgery, 105, 92-99.

https://doi.org/10.1016/j.athoracsur.2017.06.063

[13] Lansman, S.L., Goldberg, J.B., Kai, M., Tang, G.H., Malekan, R. and Spielvogel, D. (2017) Aortic Surgery in Pregnancy. The Journal of Thoracic and Cardiovascular Surgery, 153, S44-S48. https://doi.org/10.1016/j.jtcvs.2016.06.015

[14] Shihata, M., Pretorius, V. and MacArthur, R. (2008) Repair of an Acute Type A Aortic Dissection Combined with an Emergency Cesarean Section in a Pregnant Woman. Interactive Cardiovascular and Thoracic Surgery, 7, 938-940. https://doi.org/10.1510/icvts.2008.182766 